\title{
Atmospheric Circulation Response to Anomalous Siberian pÿForcing in October 2016 and its Long Range Predictability
}

\section{Tyrrell, Nicholas L.}

2019-03-16

Tyrrell , N L , Karpechko , A Y , Uotila , P \& Vihma , T 2019 , ' Atmospheric Circulation pÿResponse to Anomalous Siberian Forcing in October 2016 and its Long Range Predictability ' , Geophysical Research Letters , vol. 46 , no. 5 , pp. 2800-2810 . https://doi.org/10.1029/2018GL081580

http://hdl.handle.net/10138/302088

https://doi.org/10.1029/2018GL081580

unspecified

publishedVersion

Downloaded from Helda, University of Helsinki institutional repository.

This is an electronic reprint of the original article.

This reprint may differ from the original in pagination and typographic detail.

Please cite the original version. 


\section{Geophysical Research Letters}

\author{
RESEARCH LETTER \\ 10.1029/2018GL081580 \\ Key Points: \\ - Record strength of October 2016 \\ Warm Arctic-Cold Continent \\ pattern led to weak polar vortex and \\ negative NAO in November to early \\ December \\ - Atmospheric circulation response is \\ attributed to Siberian cold \\ anomalies but not to warm \\ anomalies in the central Arctic \\ - Subseasonal range stratospheric \\ response to October 2016 Siberian \\ temperature is reproduced by the \\ ECMWF seasonal forecast model
}

Supporting Information:

- Supporting Information S1

- Figure S1

- Figure S2

- Figure S3

Correspondence to:

N. L. Tyrrell,

nicholas.tyrrell@fmi.fi

Citation:

Tyrrell, N. L., Karpechko, A. Y., Uotila, P., \& Vihma, T. (2019). Atmospheric circulation response to anomalous Siberian forcing in October 2016 and its long-range predictability. Geophysical Research Letters, 46, 2800-2810. https:// doi.org/10.1029/2018GL081580

Received 4 DEC 2018 Accepted 18 FEB 2019

Accepted article online 22 FEB 2019

Published online 6 MAR 2019

(c)2019. American Geophysical Union. All Rights Reserved.

\section{Atmospheric Circulation Response to Anomalous Siberian Forcing in October 2016 and its Long-Range Predictability}

\author{
Nicholas L. Tyrrell ${ }^{1}$ (D), Alexey Yu. Karpechko1 ${ }^{\text {DD }}$, Petteri Uotila² ${ }^{(D)}$, and Timo Vihma ${ }^{1}$ \\ ${ }^{1}$ Finnish Meteorological Institute, Helsinki, Finland, ${ }^{2}$ Institute for Atmospheric and Earth System Research/Physics, \\ University of Helsinki, Helsinki, Finland
}

\begin{abstract}
The warm Arctic-cold continent pattern was of record strength in October 2016, providing the opportunity to test its proposed influence on large-scale atmospheric circulation. We find a record weak polar stratospheric vortex and negative North Atlantic Oscillation in November-December 2016 and link them to increased planetary wave generation associated with cold Siberian anomalies followed by troposphere-stratosphere dynamical coupling. At the same time the warm Arctic anomalies, in particular those over the Barents-Kara Seas, do not appear to play an important role in forcing the atmospheric circulation. Long-range forecasts initialized on 1 October 2016 reproduced both the weak polar vortex and negative North Atlantic Oscillation, as well as their link with the Siberian temperatures. Our results support the stratospheric pathway for atmospheric circulation forcing associated with Siberian surface anomalies and uncover a source of skill for subseasonal forecasts from October to December.
\end{abstract}

Plain Language Summary The warm Arctic-cold continent pattern is an observed, large-scale pattern of near-surface temperatures where the Arctic is warmer than average and Siberia is colder than average. This pattern was of record strength in October 2016, providing the opportunity to test its influence on the Northern Hemisphere atmospheric circulation and the possibility of skillful long-range forecasts. It has been proposed that the warm Arctic-cold continent pattern can drive large atmospheric waves, which are able to travel from the troposphere into the stratosphere, where they weaken the strong wintertime winds that make up the stratospheric polar vortex. A weakened polar vortex can then lead to changes in the surface pressure that can affect weather patterns. We find a record weak polar stratospheric vortex in late autumn 2016 and link that to cold Siberian anomalies. At the same time the warm Arctic anomalies do not appear to play an important role in forcing the atmospheric circulation. Long-range forecasts initialized in October 2016 reproduced both the weak polar vortex and resulting surface pressure patterns. Our results support the stratospheric pathway for atmospheric circulation forcing by Siberian surface anomalies and uncover a source of skill for subseasonal forecasts in the Northern Hemisphere autumn.

\section{Introduction}

The influence of Northern Hemisphere cryospheric anomalies on the large-scale, wintertime atmospheric circulation has been the focus of many recent studies, which addressed either the individual impacts of Siberian snow extent (Cohen \& Entekhabi, 1999, Fletcher et al., 2009; Peings et al., 2012; Tyrrell et al., 2018), Arctic sea ice (Honda et al., 2009; Jaiser et al., 2012, 2013; Kim et al., 2014), or the combined influence (Furtado et al., 2016). Mechanisms involving the stratospheric pathway were proposed to explain the individual effects of both these factors on the circulation (Cohen et al., 2007; Furtado et al., 2016; Kim et al., 2014) are as follows: a surface perturbation leads to an increase in vertical planetary wave activity flux into the stratosphere, the waves are absorbed in the stratosphere and slow the winds of the polar vortex, and this leads to a negative Northern Annular Mode (NAM) signal in the stratosphere which then propagates to the surface during middle-to-late winter manifesting itself in the Euro-Atlantic sector as a negative phase of the North Atlantic Oscillation (NAO). Fletcher et al. (2009) showed that surface diabatic heating/cooling produces thickness anomalies and affects the atmospheric circulation by generating Rossby waves. The response to sea ice forcing is usually associated with ice anomalies in Barents and Kara Seas in November-December, and it appears in the stratosphere between November and January 
(Furtado et al., 2016; Kim et al., 2014). Such a response is seen in observations (Kim et al., 2014; Nakamura et al., 2015) and is reproduced by some models (Kim et al., 2014), although it is model dependent (Screen et al., 2013) and not well captured by models without well resolved stratosphere (Sun et al., 2015). The dynamic response to variations in Eurasian snow cover is poorly simulated by models without artificially prescribed snow anomalies (Fletcher et al., 2009; Furtado et al., 2015; Handorf et al., 2015; Peings et al., 2017; Tyrrell et al., 2018). Furthermore, the simulated response to October snow anomalies appears between October and December (Fletcher et al., 2009; Tyrrell et al., 2018), while the observed correlations maximize in January.

Further, some studies propose that the Eurasian snow cover and Kara-Barents Sea anomalies are not independent and that the loss of sea ice in the Kara-Barents Seas leads to Eurasian cooling (Honda et al., 2009) and enhanced snow cover (e.g., Cohen et al., 2012; Liu et al., 2012), while others note that the link is mostly statistical, since both factors are related to the same wave train pattern originating in Northern Atlantic (McCusker et al., 2016; Sato et al., 2014). Nevertheless, the coincidence of warm anomalies in the central Arctic and cold anomalies over Eurasia is well documented as the warm Arctic-cold continent pattern (Overland et al., 2011).

Monthly snow anomalies in October 2016 saw near-record high values of snow extent in Eurasia (data available at Rutgers University: https://climate.rutgers.edu/snowcover/index.php; note that some discrepancies across different snow data sets exist; see Vihma, 2014) and near-record low values of Arctic sea ice (analysis available at NSIDC: http://nsidc.org/arcticseaicenews/). At the same time, tropical sea surface temperatures, another important factor influencing extratropical circulation in the Northern Hemisphere, were moderate (weak La Niña conditions and negative Indian Ocean Dipole) and therefore were not expected to provide a strong forcing. Thus, conditions were ideal to test the role of Northern Hemisphere cryospheric anomalies as a driver of atmospheric circulation. In this study we examine the atmospheric circulation response following the October 2016 surface anomalies and present evidence that cold anomalies over the Siberian region affected the large-scale atmospheric circulation and European climate in November and early December through the stratospheric pathway. Further, we show that seasonal forecasts initialized in early October forecasted the observed weakening of the polar vortex and associated negative NAM response in November suggesting potential for skillful subseasonal forecasts from October to December.

\section{Data and Methods}

We primarily used European Centre for Medium-range Weather Forecasts (ECMWF) ERA-Interim reanalysis data from 1979 to 2016 (Dee et al., 2011). To diagnose troposphere to stratosphere wave forcing, we use the zonal mean meridional eddy heat flux (HF), at $100 \mathrm{hPa}$ averaged between $40^{\circ} \mathrm{N}$ and $75^{\circ} \mathrm{N}$, which is proportional to the vertical component of the Eliassen-Palm flux (Newman et al., 2001). To demonstrate the three-dimensional propagation of quasi-stationary wave activity, we calculate the Plumb flux using monthly mean fields (Plumb, 1985). The National Center for Environmental Prediction/ National Center for Atmospheric Research (NCEP/NCAR) reanalysis data set (Kalnay et al., 1996) was used to extend the analysis back to 1957. Although quality of the reanalyses before 1979 is questionable in the stratosphere, the results based on the NCEP reanalysis are in agreement with those from ERA-I and are shown in the supporting information.

We used ensemble mean forecast and hindcast data from the ECMWF long-range forecast system initialized on 1 October between 1981 and 2016. We analyzed two model versions: System 4 (S4) (Molteni et al., 2011) which was operational in 2016 and System 5 (S5) (Johnson et al., 2018) which became operational in November 2017. The S4 ensembles consist of 15 members during 1981-2010 and 51 members after 2011. The S5 ensembles consist of 25 members. Since largely similar results are found the S4 analysis is shown in supporting information.

All correlations were performed on detrended time series, and all anomalies in reanalyses and forecasts were calculated relative to the 1981-2010 climatology. Statistical significance of correlation coefficients is tested by standard two-tailed Student's $t$ tests against the null hypothesis that the coefficients are consistent with zero. For a 36-year long time series, correlation coefficients exceeding 0.33 in absolute value are significant at $p=0.05$ significance level, assuming that each year is independent. 


\section{Results}

\subsection{Observed Surface Anomalies and Stratosphere-Troposphere Coupling in 2016}

October 2016 saw a strong warm Arctic-cold continent pattern (Figure 1a). The large-scale monthly temperature anomalies over Siberia and the central Arctic were the coldest (Siberia) and warmest (central Arctic) for the ERA-Interim time period (1979-2016) for both the detrended anomalies and the absolute temperatures. Temperature anomalies in these regions are associated with negative sea ice anomalies in the Arctic seas and positive snow extent anomalies in Siberia. Note that we focus on air temperatures, rather than snow/ice anomalies, because it is ultimately the cooling/warming of air that affects atmospheric circulation (see Fletcher et al., 2009).

There was a concurrent high-pressure system over northwestern Eurasia, centered on the Barents-Kara Sea region (Figure 1a). The pattern resembled that documented previously in conjunction with warming and sea ice loss in the region (e.g., Honda et al., 2009; Kim et al., 2014). The Siberian cold anomaly persisted into November (Figure 1b) and extended eastward toward northern Europe (supporting information Figure S3b). By late December the cold anomaly had been replaced by a zonally asymmetric warm and cold anomalies, whereas the warm central Arctic anomalies persisted throughout October to December (supporting information Figure S3c).

With Figure $1 \mathrm{~b}$ we begin to consider the relationship between surface anomalies and the stratosphere. The time series of daily Siberian $2-\mathrm{m}$ temperature $(\mathrm{T} 2 \mathrm{~m})$ anomalies $\left(40-60^{\circ} \mathrm{N}, 60-140^{\circ} \mathrm{E}\right.$, blue box in Figure 1a) are shown with the daily time series of HF. During October and November 2016 the correlation between daily Siberian T2m and daily HF maximizes at -0.7 when the HF lags by $3-4$ days. Thus, cold Siberian temperatures are associated with increased wave forcing into the stratosphere. The physical link will be explored in section 3.3, while the robustness of the statistical link will be explored in section 3.4.

Figure $1 \mathrm{c}$ shows the daily progression of polar cap $\left(60-90^{\circ} \mathrm{N}\right)$ geopotential height anomalies $(Z)$ in October, November, and December 2016, normalized by standard deviation at each pressure level. A positive $Z$ anomaly indicates a negative NAM. In early October 2016 there is a positive $Z$ anomaly throughout the troposphere and stratosphere, consistent with thermal expansion of the polar troposphere (e.g., Peings \& Magnusdottir, 2014) in response to a low sea ice extent anomaly. A positive $Z$ anomaly in the stratosphere can also be seen from late October to mid-December. Unlike in early October, the maximum anomaly was in the stratosphere indicating an anomalously warm polar stratosphere, which can be attributed to the strong forcing by planetary waves during November as diagnosed by the HF (Karpetchko \& Nikulin, 2004; Polvani \& Waugh, 2004). The episodes of positive $Z$ in the central Arctic troposphere, several of which occurred between November and December, are consistent with the downward stratosphere-troposphere coupling (Baldwin \& Dunkerton, 1999). As expected, they coincide with negative NAO phase (defined as normalized sea level pressure difference between $38^{\circ} \mathrm{N}, 26^{\circ} \mathrm{W}$ [Azores] and $65^{\circ} \mathrm{N}, 23^{\circ} \mathrm{W}$ [Iceland]) observed from mid-November to early December, as seen in the daily time series of NAO in Figure 1d. Finally, negative NAO values tend to be associated with colder north European temperatures, and a negative anomaly of almost $-5{ }^{\circ} \mathrm{C}$ is seen in Figure $1 \mathrm{~d}$ in the daily 2-m European temperatures in from mid-November to midDecember.

\subsection{Seasonal Forecasts of the Surface-Atmospheric Circulation Coupling}

For seasonal forecasts that were initialized on 1 October we assess the skill relating to the surface forcing, atmospheric response, and surface response. Figures $2 \mathrm{a}-2 \mathrm{c}$ show the relationship between mean monthly values of ERA-Interim and the ensemble mean ECMWF S5 for the years 1981 to 2016. The Siberian October T2m is well forecast (Figure 2a) and significantly correlated at $r=0.71$; although 2016 was the coldest year in the reanalysis, it was not the coldest forecast year. The forecast stratospheric response is represented in Figure $2 \mathrm{~b}$ by the monthly mean November zonal mean zonal winds at $10 \mathrm{hPa}$ and $60^{\circ} \mathrm{N}$. The correlation for the zonal winds over the whole 36-year period is 0.49 (significant at $p=0.05$ ). In particular, the weak winds in 2016 are predicted. Note that the magnitude of the forecasted anomalies is generally smaller than that in observations, due to weakening of the signal with forecast time as the influence of initial condition reduces. The subsequent surface response is represented by the polar cap geopotential height at $1,000 \mathrm{hPa}$ in Figure 2c. The correlation coefficient is $r=0.24$. This corresponds to an explained variance of $\sim 5.8 \%$, which suggests a minor skill for November-December. That small skill is further reduced if 
(a)

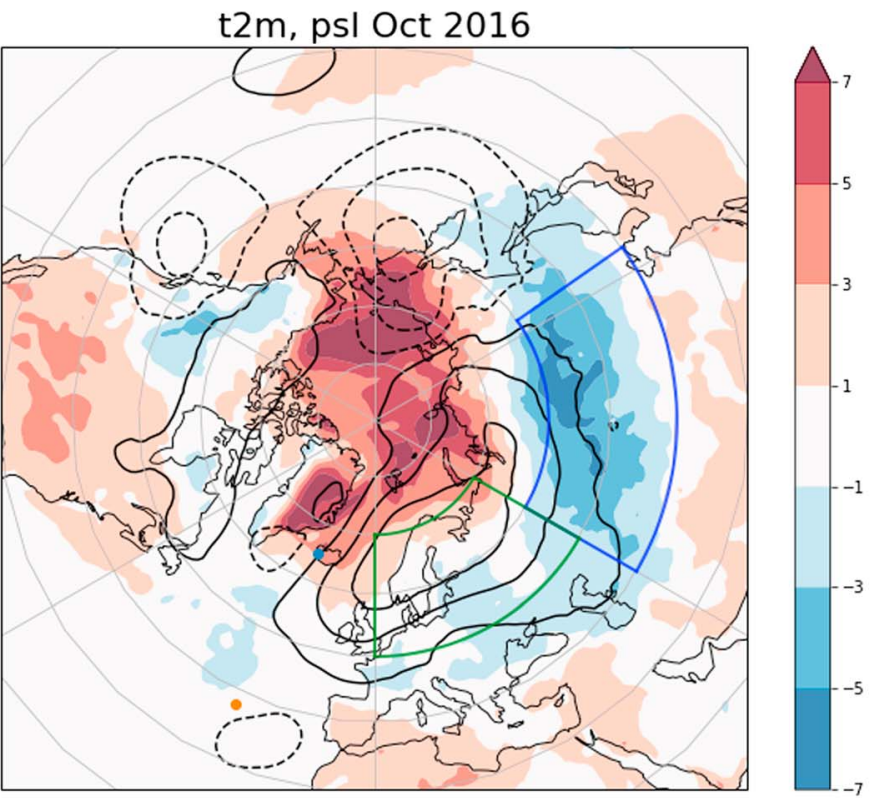

(b)

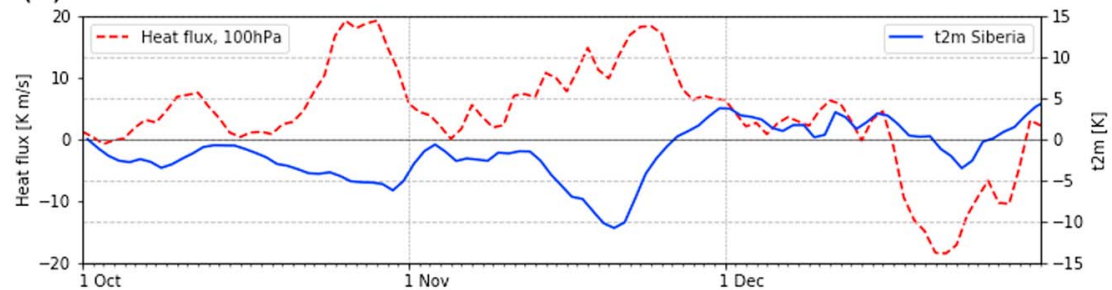

(c)

Z polar cap anom. 2016, 60-90N
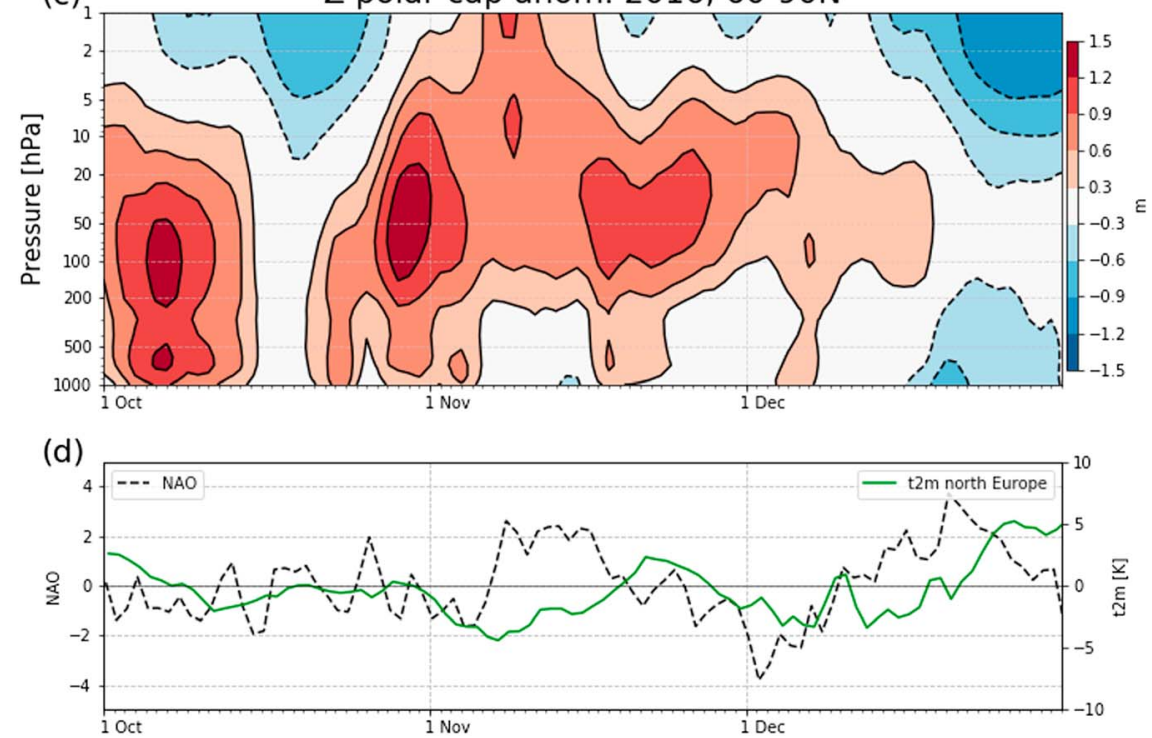

Figure 1. October-December 2016 ERA-interim reanalysis data. (a) October 2016 monthly mean anomalous 2-m temperature (shading) and mean sea level pressure anomalies (contoured every $3 \mathrm{hPa}$; dashed lines for negative anomalies). (b) Time series of anomalous heat flux at $100 \mathrm{hPa}, 45-75^{\circ} \mathrm{N}$, and anomalous Siberian 2-m temperature averaged over $40-60^{\circ} \mathrm{N}, 60-140^{\circ} \mathrm{E}$, blue box in (a). (c) Time series of normalized polar cap $\left(60-90^{\circ} \mathrm{N}\right)$ geopotential height anomalies from 1,000 to $1 \mathrm{hPa}$. (d) Time series of daily NAO calculated as the difference between normalized sea level pressure at $38^{\circ} \mathrm{N}, 26^{\circ} \mathrm{W}$ (Azores, orange dot in [a]) and $65^{\circ} \mathrm{N}, 23^{\circ} \mathrm{W}$ (Iceland, blue dot in [a]), and anomalous northern European 2-m temperature averaged over $50-70^{\circ} \mathrm{N}, 0-50^{\circ} \mathrm{E}$ (green box in [a]). 

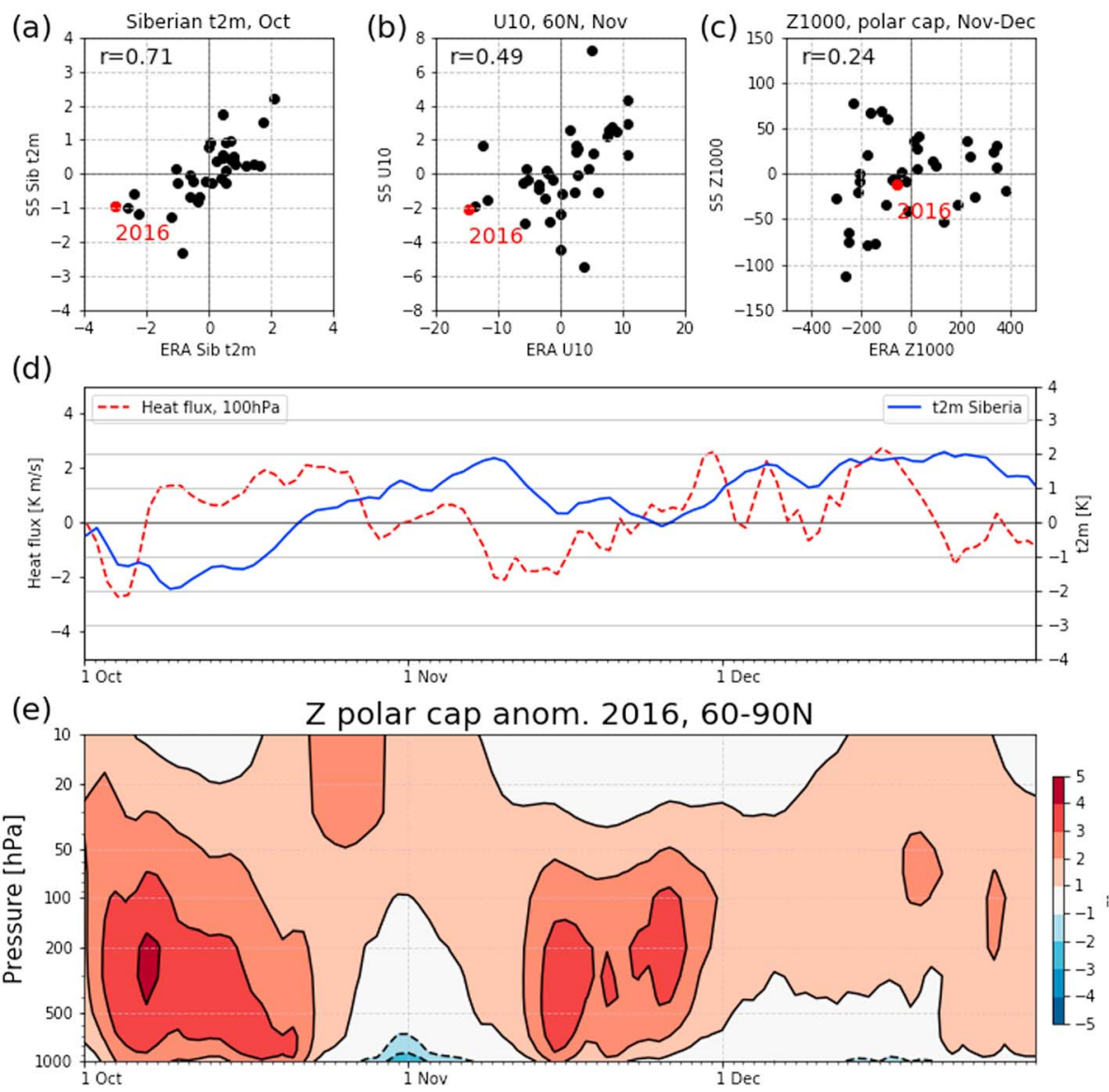

(f)

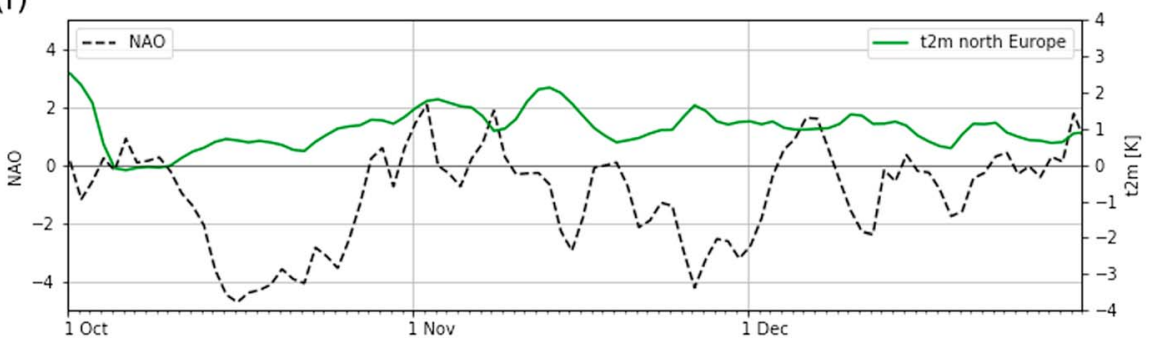

Figure 2. October-December 2016 ECMWF System 5, all forecasts initialized on 1 October. (a) Scatterplot of ERA-interim and ECMWF S5 October mean Siberian T2m averaged over $40-60^{\circ} \mathrm{N}, 60-140^{\circ} \mathrm{E}$. (b) Scatterplot of ERA-interim and ECMWF S5 November zonal mean zonal winds at $60^{\circ} \mathrm{N}$ and $10 \mathrm{hPa}$. (c) Scatterplot of ERA-interim and ECMWF S5 November-December normalized polar cap $\left(60-90^{\circ} \mathrm{N}\right)$ geopotential height anomalies at 1,000 hPa. (d) Time series of anomalous heat flux at $100 \mathrm{hPa}, 45-75^{\circ} \mathrm{N}$ and anomalous Siberian 2-m temperature defined over $40-60^{\circ} \mathrm{N}, 60-140^{\circ} \mathrm{E}$. (c) Time series of normalized polar cap $\left(60-90^{\circ} \mathrm{N}\right)$ geopotential height anomalies from 1,000 to $10 \mathrm{hPa}$. (d) Time series of daily NAO calculated as the difference between normalized sea level pressure at $38^{\circ} \mathrm{N}, 26^{\circ} \mathrm{W}$ (Azores) and $65^{\circ} \mathrm{N}, 23^{\circ} \mathrm{W}$ (Iceland) and anomalous northern European 2-m temperature defined over $50-70^{\circ} \mathrm{N}, 0-50^{\circ} \mathrm{E}$.

using the simple NAO index (not shown), where no correlation is found between 1981 and 2016 November NAO in ERA-Interim and S5.

We now compare the daily 2016 S5 forecasts (Figures $2 d-2 f$ and supporting information Figures S3d-S3f) and observations (Figures 1b-1d). Cold Siberian temperatures were forecast for much of October, and the relationship between cold Siberian temperatures and increased HF is consistent with observations (Figures $1 \mathrm{~b}$ and $2 \mathrm{~d}$ ). However, the cold Siberian temperatures and increased HF did not extend into November. The positive stratospheric polar cap geopotential height $(Z)$ anomalies in November are reproduced, indicative of vortex weakening and in agreement with observations (Figure 2e). Positive $Z$ anomalies are simulated through most of the troposphere and stratosphere starting from early October and extending 
until the end of December, while they ended around mid-December in observations (Figure 1c). Finally, a negative NAO was forecast during November (Figure 2f); however, no cooling of northern European temperatures in response to the NAO was forecast, as seen in observations. The forecasts ECMWF S4 were qualitatively similar and are shown in supporting information Figures S1 and S3.

Overall, the diagnostics shown in Figure 2 suggest that the model is capable of capturing the key features of atmospheric dynamical response to the Siberian surface forcing in October and making a skillful forecast of stratospheric circulation anomalies beyond a 1-month period. Although there is little skill in subseasonal NAO forecast when looking at the whole 36-year period, the model captures the response to the 2016 forcing qualitatively well, indicating the potential for a skillful NAO forecast related to the stratospheric anomalies following strong surface forcing like in 2016. On the other hand, the expected cool North European surface temperature response to a negative NAO is not present (supporting information Figure S3). A similar result is seen in Scaife et al. (2014), where there was more skill in seasonal NAO forecasts than in Northern European temperature forecasts, despite the well-documented connection between the two quantities.

\subsection{Mechanisms}

To understand the mechanisms responsible for the coupling between surface anomalies and atmospheric circulation response in October 2016, we start by analyzing the upper-tropospheric quasi-stationary Rossby wave activity. Figure 3a shows anomalous eddy geopotential height (defined as the deviation of geopotential height from its zonal mean) and the vertical and horizontal components of the Plumb flux at $250 \mathrm{hPa}$ in October 2016. There was a wave train propagating from North Atlantic across Eurasia with an upper level high over Barents-Kara-Greenland (BKG) Seas and an upper level low over western Siberia, which led to a strengthening of the climatological Siberian low. Honda et al. (2009) proposed that such a wave train can be generated by ice loss over the Kara and Barents Seas; however, a modeling study by McCusker et al. (2016) found only minor contribution from ice loss to forcing Rossby wave trains. Sato et al. (2014) analyzed similar wave trains in association with central Arctic warming and Siberian cooling in observations and showed that these wave trains originate from the North Atlantic, which is consistent with what we find in October 2016 (Figure 3a). Sato et al. (2014) proposed that the wave train may be associated with the positive phase of the Atlantic Multidecadal Oscillation; however, we do not further investigate the origin of the wave train in 2016.

Figure $3 \mathrm{~b}$ shows near-surface temperature advection due to anomalous winds (Va) acting on climatological temperature gradient ( $\nabla \mathrm{Tc}),(\mathrm{Va} \cdot \nabla \mathrm{Tc})$ in October 2016. We find strong cooling in Siberia due to the advection of cold air (Figure 3b). This is consistent with results by Takaya and Nakamura (2005), Honda et al. (2009), and McCusker et al. (2016) who found that temperature advection from the central Arctic due to anomalous winds associated with the Atlantic wave train contributes to Eurasian cooling and associated amplification of the Siberian anticyclone. A near-surface cooling forces circulation through conservation of potential vorticity (Hoskins \& Karoly 1981; Takaya \& Nakamura, 2005). An anomalous low downwind of the region of the surface cooling can be recognized in the upper troposphere in November (Figures 3c and 3e), an expected response to the cooling (Fletcher et al., 2009). This anomalous low projects on the climatological low over Siberia and constructively interferes and amplifies tropospheric wavenumber 1 (Figures $3 \mathrm{c}$ and $3 \mathrm{~d}$ ). To confirm the contribution of surface cooling to the amplification of upper level planetary waves, we correlate the monthly mean Siberian T2m anomalies for October with the November amplitude of wavenumber 1 at $250 \mathrm{hPa}$, for the period 1979-2016. We calculate the monthly wavenumber 1 amplitude as the mean of the wave 1 eddy geopotential height over the area $40-70^{\circ} \mathrm{N}, 100-220^{\circ} \mathrm{E}$, chosen to cover the climatological maximum of wavenumber 1 at $250 \mathrm{hPa}$ (i.e., Figure 3d). The correlation is 0.43 and robust for a range of lags between 2 weeks and 1 month, indicating a significant relationship between surface temperature and wavenumber 1 and suggesting that there was a contribution of Siberian cooling to the upper level trough in October-November 2016.

The role of constructive wave interference is further illustrated in Figures $3 \mathrm{e}$ and $3 \mathrm{f}$, which show cross sections of both anomalous and climatological components of the total and wavenumber 1 eddy geopotential heights. The colocation of climatological and anomalous waves in the upper troposphere and the lower stratosphere indicates that constructive interference of anomalous and climatological waves (Garfinkel et al., 2010; Ineson \& Scaife, 2009; Smith et al., 2010) played a role in increasing upward wave activity propagation 
(a) Z250 eddy total, Oct 2016

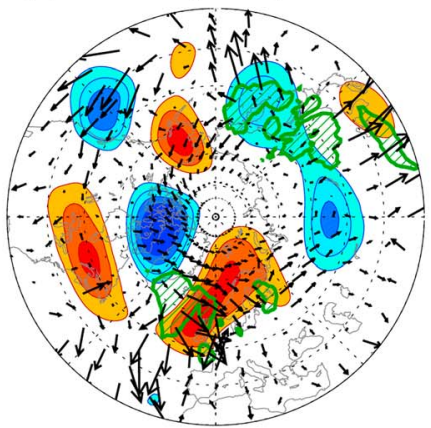

(c) Z250 eddy total, Nov 2016

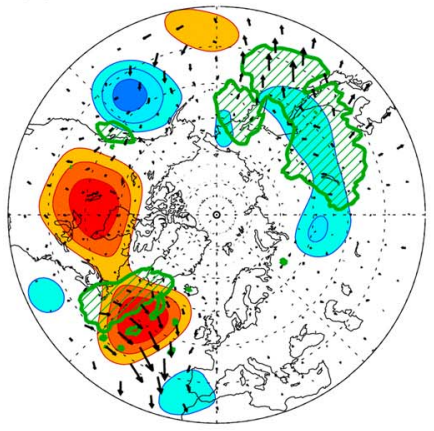

(e) Z eddy total, Nov 2016
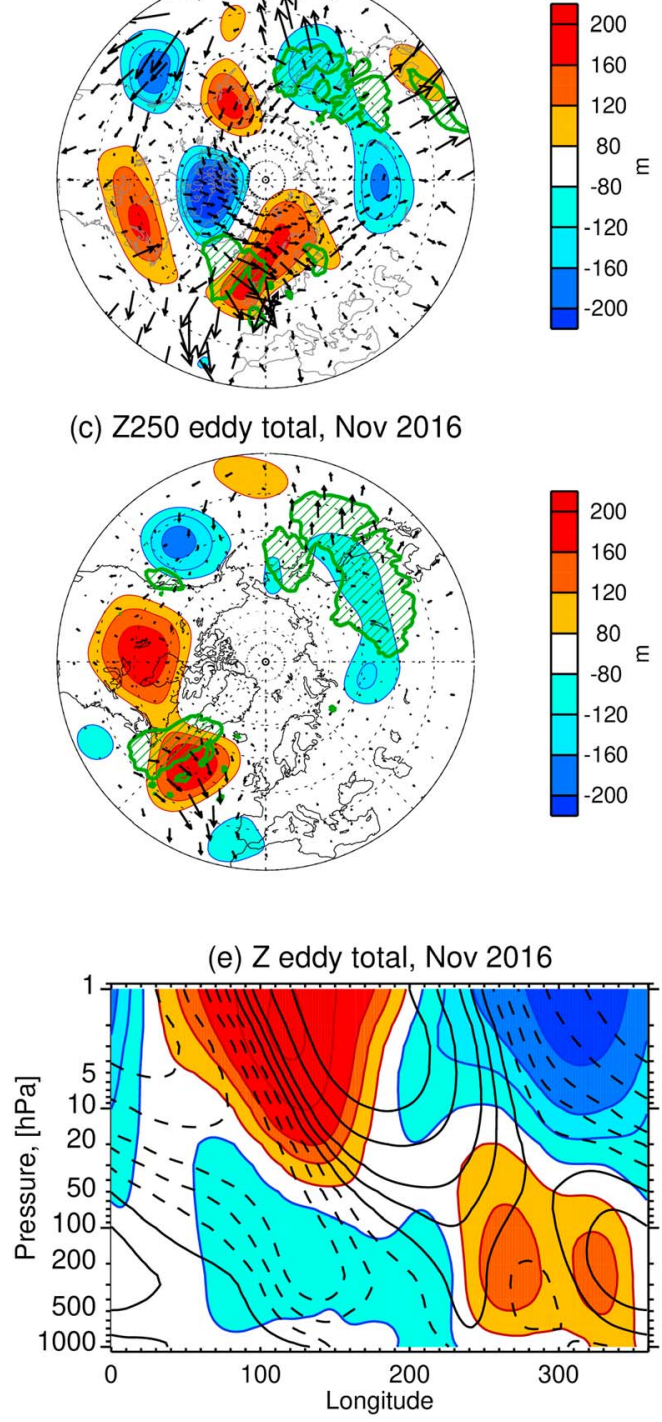

(b) T975 anom. adv., Oct 2016

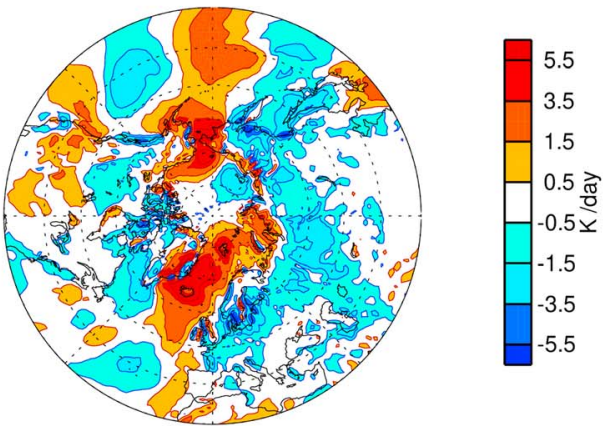

(d) Z250 eddy wave 1, Nov 2016

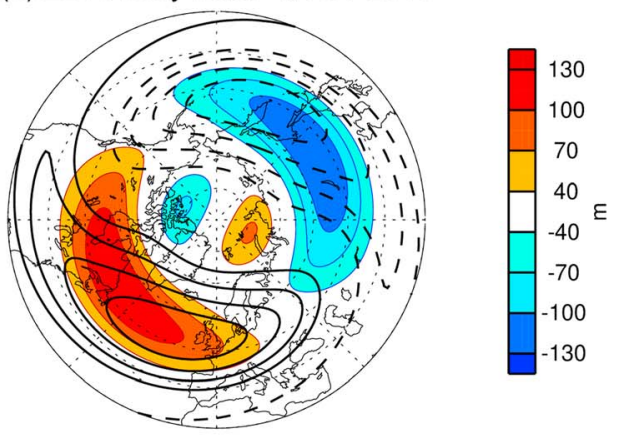

(f) Z eddy wave 1, Nov 2016

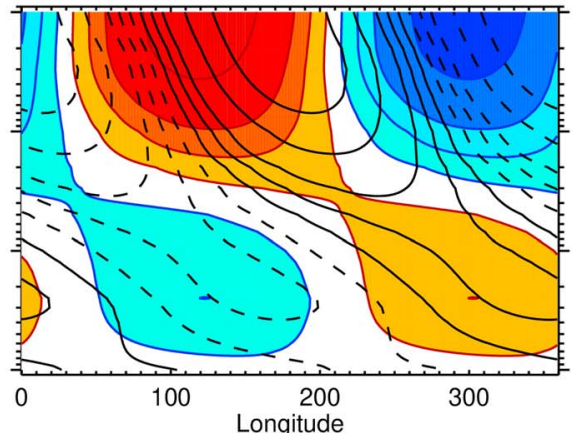

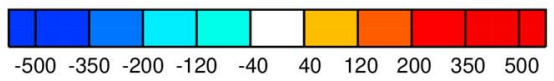

Figure 3. (a) ERA-interim anomalous eddy geopotential height (shading), vertical component of the Plumb flux (green contours), and horizontal components of the Plumb flux (vectors) at $250 \mathrm{hPa}$ in October 2016. (b) ERA-interim anomalous temperature advection $\left(V_{a} \cdot \nabla T_{c}\right)$ at $975 \mathrm{hPa}$ in October 2016. (c) ERA-interim anomalous eddy geopotential height (shading), horizontal (vectors), and vertical (green contours) components of the Plumb flux at $250 \mathrm{hPa}$ in November 2016. (d) Wavenumber 1 component of the anomalous (shading) and climatological (contours) eddy geopotential height at $250 \mathrm{hPa}$ in November 2016. (e, f) Cross section of ERA-I (e) total and (f) wavenumber 1 eddy geopotential height at 50$60 \mathrm{~N}$ in November 2016. Shown are anomalous (shading) and climatological (contours) components.

to the stratosphere in November 2016. Note that the region with maximum upward wave propagation near the tropopause, as indicated by the vertical component of the Plumb flux, is located eastern Siberia in November (Figure 3c). Other eddies appearing in Figures 3a and 3c, in particular the wave train propagating across North America and Atlantic, could also have played a role in forcing the stratosphere in October and November 2016. In October an upward wave flux from the European-Atlantic sector, which was likely related to the development of the Scandinavian high and blocking, was comparable to that from Siberia (Figure 3a); hence, during October both regions likely contributed to wave flux into the stratosphere. 
Since our focus is on the Siberian influence detailed analysis of the Scandinavian blocking is outside the scope of our paper.

The mechanism of the coupling between the October-November surface anomalies and the NovemberDecember atmospheric circulation in 2016 is summarized as follows: the Atlantic wave train strengthened the climatological upper level low over Siberia and led to enhanced cooling of the Siberian region via advection; the surface cooling further strengthened the upper level low; constructive interference between this anomalous low and planetary wavenumber 1 led to enhanced upward wave propagation into the stratosphere; the stratospheric zonal winds were weakened by this increased wave propagation.

\subsection{Generalization to Full Observational Record}

The extreme surface anomalies over Siberia in October 2016 made it a useful case study for the surface forcing of the stratospheric circulation; however, it is difficult to draw generalized conclusions from a single event. Hence, we now look to extend these results to the full period of the ERA-Interim and forecast data sets. Figure 4a shows the detrended time series of October mean T2m averaged over Siberia and BKG Seas. We include the BKG region as near-surface thermal anomalies in that region that have been linked to atmospheric circulation anomalies in a number of studies (e.g., Cohen et al., 2007; Honda et al., 2009). The surface to stratosphere influence is shown with the HF. We use a shifted timing for the HF (16 October to 15 November) to allow for the lag due to upward propagation of Rossby waves. We find similar results for a range of lags and averaging periods in October-November for the HF. The correlation between the October-November $\mathrm{HF}$ and October Siberian $\mathrm{T} 2 \mathrm{~m}$ time series is -0.51 , significant at $p=0.05$, while the correlation between October BKG Seas temperatures and the October-November HF is 0.28 and not significant. The Siberian and BKG Seas temperature time series are correlated at -0.31 , and creating a time series by linearly combining the two and correlating that with HF can yield a correlation value of -0.52 , not a significant improvement from the Siberian time series alone. We note that years when warm BKG Seas coincided with cold Siberia (1981, 2000, and 2016) there was a strong HF, but years with a warm BKG Seas anomaly without a cold Siberia (i.e., 2007, 2010, 2011, and 2012) did not exhibit a similar stratospheric wave response. Similar analysis is presented in supporting information Figure S2 using the NCEP reanalysis data and ECMWF S4 data. The link between the OctoberNovember $\mathrm{HF}$ and October Siberian $\mathrm{T} 2 \mathrm{~m}$ time series is reproduced in the longer record of NCEP/NCAR reanalysis (1958-2016) although with a somewhat weaker magnitude $(r=-0.35$, significant at $p=0.05$ ). If we split the NCEP data to compare with ERA-Interim, we find values of $r=-0.45$, $p<0.05$ for $1979-2016$ and $r=-0.36, p=0.10$ for $1958-1978$. Therefore, the reduced correlation in the NCEP/NCAR reanalysis is mostly due to weaker connection in the earlier years. The weaker connection before 1979 may indicate nonstationarity in the teleconnection between Siberian temperatures and stratospheric forcing, although the fact that there were fewer stratospheric observations before 1979 does not allow us to robustly assess stationarity.

The pointwise correlation between T2m in October and the October-November HF in Figure 4b shows a large area of negative correlations over Siberian, with maximum absolute values exceeding 0.5 . In the central Arctic, the area of weak positive correlations is largely restricted to the BKG region and although this is the area where sea ice extent is associated with a weakening of the stratospheric vortex (e.g., Kim et al., 2014), the area of positive correlations also extends further south and west to an area which is mostly ice free in October suggesting that this correlation is not necessarily due to sea ice loss.

The same pointwise correlation was calculated for the S5 forecasts, initialized on 1 October for years 1981-2016. The simulated temperature-HF correlation field (Figure 4c) does not have the weak coupling observed between HF and BKG temperatures, seen in the observed counterpart (Figure 2b). The model captures the observed coupling between Siberian temperatures and HF, although the maximum is shifted southwest.

When December HF is used instead of November HF, the correlations with October Siberian T2m drop to near zero (not shown), suggesting that the influence of Siberian temperature anomalies on planetary wave generation is limited to a period of about 1 month. This is consistent with modeling studies of Fletcher et al. (2009) and Tyrrell et al. (2018) who both showed that upward wave activity fluxes due to October Siberian snow anomalies maximize in October-November. 


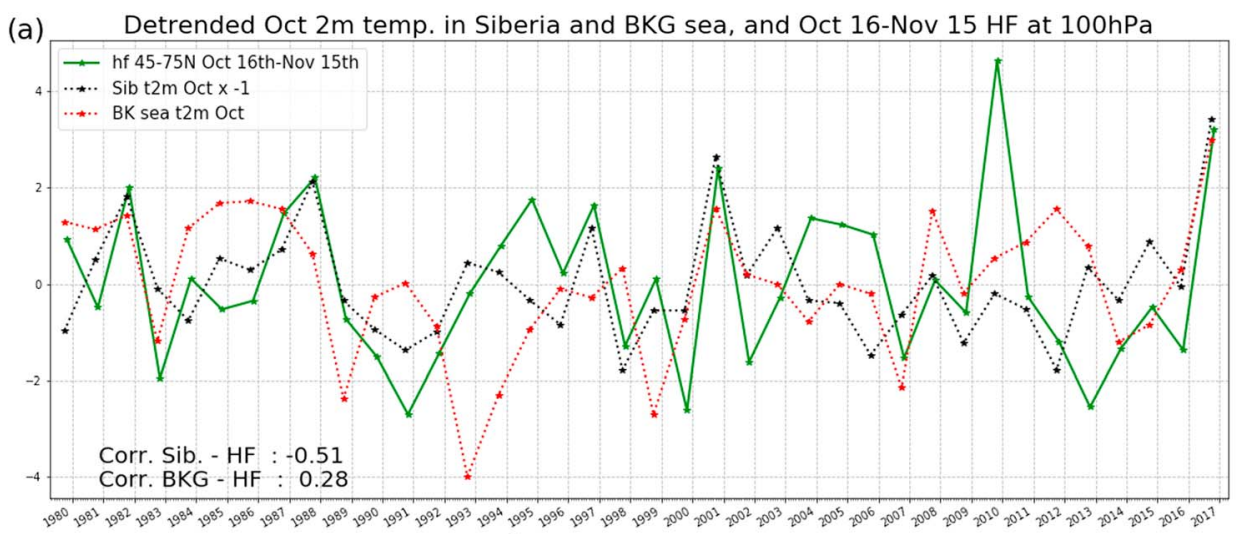

Corr, Oct t2m and Oct 16-Nov 15 HF 45N-75N

(b)

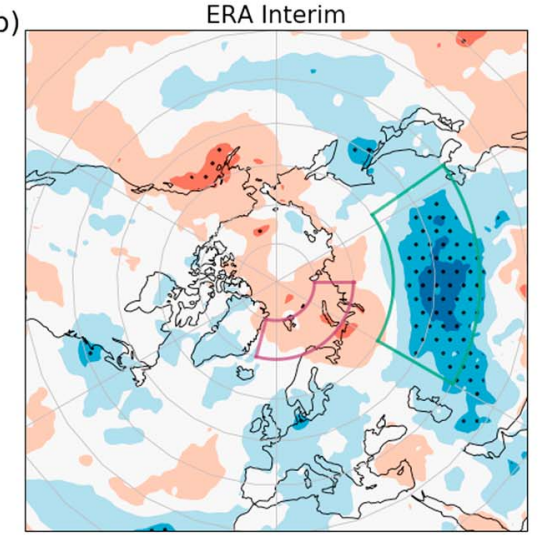

Corr, Z polar cap and Siberian Oct $\mathrm{t} 2 \mathrm{~m}$ (c)
ECMWF S5
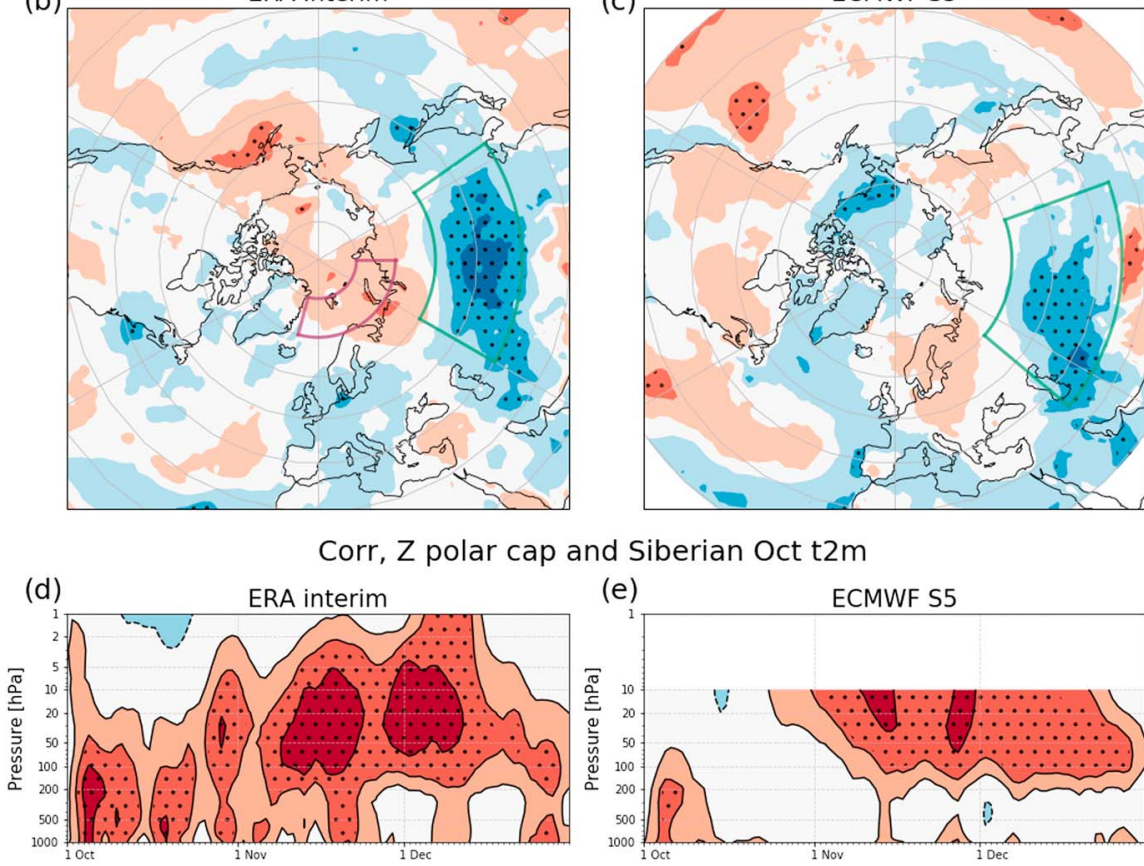

ECMWF S5

(e)

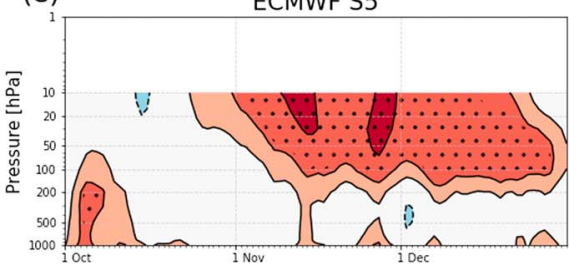

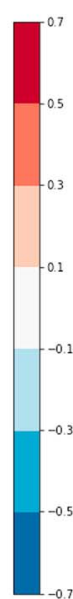

$-0.7$

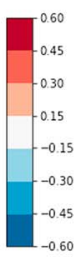

Figure 4. (a) Time series of ERA-interim October mean T2m averaged over Siberia (black, $40-60^{\circ} \mathrm{N}, 60-140^{\circ} \mathrm{E}$, the area marked is in (b); Siberian temperature is multiplied by -1 for easier comparison to other time series) and Barents, Kara, and Greenland Seas (red, $70^{\circ} \mathrm{N}$ to $80^{\circ} \mathrm{N}, 15^{\circ} \mathrm{W}$ to $90^{\circ} \mathrm{E}$, area marked in [b]). Also shown is the November mean meridional eddy heat flux at $100 \mathrm{hPa}, 45-75^{\circ} \mathrm{N}$ (green). (b, c) Correlation coefficients between October 2-m temperatures and the mean 15 October to 16 November eddy heat flux at $100 \mathrm{hPa}, 40-75^{\circ} \mathrm{N}$ in (b) ERA-interim and (c) ECMWF S5 forecast system initialized on 1 October . (d, e) Correlation between October mean Siberian T2m and daily normalized polar cap geopotential height for (d) ERA-interim and (e) ECMWF S5 forecast system initialized on 1 October. Dots in (be) mark correlations significant at $p<0.05$.

To further quantify the link between surface forcing and atmospheric circulation, we show in Figure 4d (ERA-Interim) and Figure 4e (S5) the correlation coefficients between daily $Z$ anomalies and the October Siberian T2m anomalies. Since positive polar cap Z anomalies correspond to negative Siberian T2m anomalies, the correlation is multiplied by -1 to facilitate comparison between Figures $4 \mathrm{~d}$ and $4 \mathrm{e}$ and $1 \mathrm{c}$ and 2c. In October, positive correlations in ERA-I are present in the troposphere, suggesting higher-than-normal $Z$ anomalies and thus temperatures, in the central Arctic during years with a cold Siberia (i.e., the warm Arctic-cold continent pattern). These significant October tropospheric correlations are not well simulated in S5. In November-December, significant correlations are found in ERA-I and S5 in the stratosphere, which is consistent with weakening of the polar vortex following Siberian surface cooling (e.g., Figure 1c and 2c). Significant correlations between Siberian temperature and $Z$ anomalies extend until the end of December, which suggests that an early ending of stratospheric anomalies in 
2016 by mid-December (Figure 1c) is not typical for Siberian forcing and likely results from internal variability.

\section{Conclusions}

Temperature anomalies in October 2016 represented an extreme example of the warm Arctic-cold continents pattern and thus an excellent opportunity to test the proposed influence of the Northern Hemisphere cryosphere on the polar vortex. In this paper we have shown that the large Siberian cold anomaly in October 2016 was associated with increased planetary wave flux into the stratosphere in OctoberNovember, a weakened polar vortex from November into early December, and subsequently a surface signal of a negative NAO and cooling of northern European T2m. However, it is difficult to make generalized attributions based a single case; hence, a statistical analysis of the observational record is included to strengthen our findings. Lagged correlation maps between T2m and eddy HF indicate a strong connection between the Siberian cooling and an increased planetary wave flux into the stratosphere, and correlations with the polar cap geopotential height elucidate the atmospheric structure and timing of the response to Siberian forcing.

There is an ongoing discussion about whether the recent decrease in Boreal autumn Arctic sea ice has a remote influence on midlatitude weather systems (e.g., Overland et al., 2015; Vihma, 2014). In our analysis, we found a stronger influence of Siberian T2m on the large-scale atmospheric circulation in comparison with that from the Barents-Kara-Greenland seas temperature, which is generally linked to melting Arctic sea ice. However, most of the other studies on Arctic sea ice forcing have focused on NovemberDecember ice anomalies, while the present study focuses on October anomalies. Since there is little sea ice in the Barents-Kara Seas in October, the warming in 2016 was likely associated with atmospheric heat advection. Focusing on the Siberian anomalies, we associate the anomalous Siberian cooling in October 2016 with cold Arctic air advection by Rossby wave train propagating from the Atlantic. The cooling was followed by anomalous Rossby wave generation and upward propagation to the stratosphere. Although different parts of the presented mechanism chain have been discussed in a number of papers, it has not previously been demonstrated to operate in a particular year, as is done here.

We have demonstrated that Siberian surface forcing of atmospheric large-scale circulation is represented in the ECMWF seasonal forecast system. Several studies have documented the skill of wintertime seasonal forecasts (Butler et al., 2016; Scaife et al., 2014; Stockdale et al., 2015); however, little has been known about sources of skill in Boreal autumn. Although this forcing explains only small fraction of surface NAO variability during late autumn to early winter, we believe that the existence of atmospheric predictability mechanisms beyond 1 month and their representation in the forecast model documented here is encouraging and useful for interpreting model predictions.

Acknowledgments

N. T., A. Y. K., and T. V. are funded by the Academy of Finland (grants 286298, 294120, and 283101, respectively). P. U. is funded by the EC Marie Curie Support Action LAWINE (grant 707262). The authors thank Prof. Adam Scaife for useful discussions and comments on an earlier version of the manuscript, and the two anonymous reviewers for their helpful suggestions. ECMWF products are available from the ECMWF data servers in the ECMWF website (http://www. ecmwf.int/).

\section{References}

Baldwin, M. P., \& Dunkerton, T. J. (1999). Propagation of the Arctic Oscillation from the stratosphere to the troposphere. Journal of Geophysical Research, 104(D24), 30,937-30,946.

Butler, A. H., Arribas, A., Athanassiadou, M., Baehr, J., Calvo, N., Charlton-Perez, A., et al. (2016). The climate historical forecast project: Do stratosphere-resolving models make better seasonal climate predictions in boreal winter? Quarterly Journal of the Royal Meteorological Society, 142, 1413-1427.

Cohen, J., \& Entekhabi, D. (1999). Eurasian snow cover variability and Northern Hemisphere climate predictability. Geophysical Research Letters, 26, 345-348.

Cohen, J. L., Barlow, M., Kushner, P., \& Saito, K. (2007). Stratosphere-troposphere coupling and links with Eurasian land-surface variability. Journal of Climate, 20, 5335-5343.

Cohen, J. L., Furtado, J. C., Barlow, M. A., Alexeev, V. A., \& Cherry, J. E. (2012). Arctic warming, increasing snow cover and widespread boreal winter cooling. Environmental Research Letters, 7(1), 014007.

Dee, D. P., Uppala, S. M., Simmons, A. J., Berrisford, P., Poli, P., Kobayashi, S., et al. (2011). The ERA-Interim reanalysis: Configuration and performance of the data assimilation system. Quarterly Journal of the Royal Meteorological Society, 137, 553-597. https://doi.org/10.1002/ qj. 828

Fletcher, C. G., Hardiman, S. C., Kushner, P. J., \& Cohen, J. L. (2009). The dynamical response to snow cover perturbations in a large ensemble of atmospheric GCM integrations. Journal of Climate, 22, 1208-1222.

Furtado, J. C., Cohen, J. L., Butler, A. H., Riddle, E. E., \& Kumar, A. (2015). Eurasian snow cover variability and links to winter climate in the CMIP5 models. Climate Dynamics, 45, 2591. https://doi.org/10.1007/s00382-015-2494-4

Furtado, J. C., Cohen, J. L., \& Tziperman, E. (2016). The combined influences of autumnal snow and sea ice on Northern Hemisphere winters. Geophysical Research Letters, 43, 3478-3485. https://doi.org/10.1002/2016GL068108

Garfinkel, C. I., Hartmann, D. L., \& Sassi, F. (2010). Tropospheric precursors of anomalous Northern Hemisphere stratospheric polar vortices. Journal of Climate, 23, 3282-3299. 
Handorf, D., Jaiser, R., Dethloff, K., Rinke, A., \& Cohen, J. L. (2015). Impacts of Arctic sea ice and continental snow cover changes on atmospheric winter teleconnections. Geophysical Research Letters, 42, 2367-2377. https://doi.org/10.1002/2015GL063203

Honda, M., Inoue, J., \& Yamane, S. (2009). Influence of low Arctic sea-ice minima on anomalously cold Eurasian winters. Geophysical Research Letters, 36, L08707. https://doi.org/10.1029/2008GL037079

Hoskins, B., \& Karoly, D. (1981). The steady response of a spherical atmosphere to thermal and orographic forcing. Journal of Atmospheric Science, 38, 1179-1196.

Ineson, S., \& Scaife, A. A. (2009). The role of the stratosphere in the European response to El Niño. Nature Geoscience, 2, 32-36. https://doi. org/10.1038/NGEO381

Jaiser, R., Dethloff, K., \& Handorf, D. (2013). Stratospheric response to Arctic sea ice retreat and associated planetary wave propagation changes. Tellus A, 65(1), 19375. https://doi.org/10.3402/tellusa.v65i0.19375

Jaiser, R., Dethloff, K., Handorf, D., Rinke, A., \& Cohen, J. (2012). Impact of sea ice cover changes on the Northern Hemisphere atmospheric winter circulation. Tellus A, 64, 11595.

Johnson, S. J., Stockdale, T. N., Ferranti, L., Balmaseda, M. A., Molteni, F., Magnusson, L., et al. (2018). SEAS5: The new ECMWF seasonal forecast system. Geoscientific Model Development Discussion, 1-44. In review. https://doi.org/10.5194/gmd-2018-228

Kalnay, E., Kanamitsu, M., Kistler, R., Collins, W., Deaven, D., Gandin, L., et al. (1996). The NCEP/NCAR 40-year reanalysis project. Bulletin of the American Meteorological Society, 77(3), 437-471. https://doi.org/10.1175/1520-0477

Karpetchko, A., \& Nikulin, G. (2004). Influence of early winter upward wave activity flux on midwinter circulation in the stratosphere and troposphere. Journal of Climate, 17(22), 4443-4452.

Kim, B. M., Son, S. W., Min, S. K., Jeong, J. H., Kim, S. J., Zhang, Z., et al. (2014). Weakening of the stratospheric polar vortex by Arctic seaice loss. Nature Communications, 5(1), 4646. https://doi.org/10.1038/ncomms5646

Liu, J., Curry, J. A., Wang, H., Song, M., \& Horton, R. (2012). Impact of declining Arctic sea ice on winter snowfall. Proceedings of the National Academy of Sciences of the USA, 109(11), 4074-4079. https://doi.org/10.1073/pnas.1114910109

McCusker, K. E., Fyfe, J. C., \& Sigmond, M. (2016). Twenty-five winters of unexpected Eurasian cooling unlikely due to Arctic sea-ice loss. Nature Geoscience, 9, 838-842. https://doi.org/10.1038/ngeo2820

Molteni, F., Stockdale, T., Balmaseda, M., Balsamo, G., Buizza, R., Ferranti, L., et al. (2011). The new ECMWF seasonal forecast system (System 4), ECMWF Technical Memorandum, 656, 49.

Nakamura, T., Yamazaki, K., Iwamoto, K., Honda, M., Miyoshi, Y., Ogawa, Y., \& Ukita, J. (2015). A negative phase shift of the winter $\mathrm{AO} / \mathrm{NAO}$ due to the recent Arctic sea-ice reduction in late autumn. Journal of Geophysical Research: Atmospheres, 120, $3209-3227$. https://doi.org/10.1002/2014JD022848

Newman, P. A., Nash, E. R., \& Rosenfield, J. E. (2001). What controls the temperature of the Arctic stratosphere during the spring? Journal of Geophysical Research, 106, 19,999-20,010.

Overland, J., Francis, J. A., Hall, R., Hanna, E., Kim, S.-J., \& Vihma, T. (2015). The melting Arctic and mid-latitude weather patterns: Are they connected? Journal of Climate, 28(20), 7917-7932. https://doi.org/10.1175/JCLI-D-14-00822.1.

Overland, J. E., Wood, K. R., \& Wang, M. (2011). Warm Arctic-cold continents: Climate impacts of the newly open arctic sea. Polar Research, 30(1), 1-14. https://doi.org/10.3402/polar.v30i0.15787

Peings, Y., Douville, H., Colin, J., Saint Martin, D., \& Magnusdottir, G. (2017). Snow-(N) AO teleconnection and its modulation by the Quasi-Biennal Oscillation. Journal of Climate, 24, 10,211-10,235.

Peings, Y., \& Magnusdottir, G. (2014). Response of the wintertime Northern Hemisphere atmospheric circulation to current and projected Arctic sea ice decline: A numerical study with CAM5. Journal of Climate, 27, 244-264.

Peings, Y., Saint-Martin, D., \& Douville, H. (2012). A numerical sensitivity study of the influence of Siberian snow on the northern annular mode. Journal of Climate, 25, 592-607. https://doi.org/10.1175/JCLI-D-11-00038.1

Plumb, R. A. (1985). On the three-dimensional propagation of stationary waves. Journal of the Atmospheric Sciences, 42(3), 217-229.

Polvani, L. M., \& Waugh, D. W. (2004). Upward wave activity flux as a precursor to extreme stratospheric events and subsequent anomalous surface weather regimes. Journal of Climate, 17, 3548-3554.

Sato, K., Inoue, J., \& Watanabe, M. (2014). Influence of the Gulf Stream on the Barents Sea ice retreat and Eurasian coldness during early winter. Environmental Research Letters, 9, 084009. https://doi.org/10.1088/1748-9326/9/8/084009

Scaife, A. A., Arribas A., Blockley E., Brookshaw A., Clark R. T., Dunstone N., et al. (2014), Skillful long-range prediction of European and North American winters. Geophysical Research Letters, 41, 2514-2519. https://doi.org/10.1002/2014GL059637

Screen, J. A., Simmonds, I., Deser, C., \& Tomas, R. (2013). The atmospheric response to three decades of observed Arctic sea ice loss Journal of Climate, 26, 1230-1248.

Smith, K. L., Fletcher, C. G., \& Kushner, P. J. (2010). The role of linear interference in the annular mode response to extratropical surface forcing. Journal of Climate, 23, 6036-6050. https://doi.org/10.1175/2010JCLI3606.1

Stockdale, T. N., Molteni, F., \& Ferranti, L. (2015). Atmospheric initial conditions and the predictability of the Arctic Oscillation. Geophysical Research Letters, 42, 1173-1179. https://doi.org/10.1002/2014GL062681

Sun, L., Deser, C., \& Tomas, R. A. (2015). Mechanisms of stratospheric and tropospheric circulation response to projected Arctic sea ice loss. Journal of Climate, 28, 7824-7845. https://doi.org/10.1175/JCLI-D-15-0169.1

Takaya, K., \& Nakamura, H. (2005). Mechanisms of intraseasonal amplification of the cold Siberian high. Journal of Atmospheric Science, $62,4423-4440$

Tyrrell, N. L., Karpechko, A. Y., \& Räisänen, P. (2018). The influence of Eurasian snow extent on the northern extratropical stratosphere in a QBO resolving model. Journal of Geophysical Research: Atmospheres, 123, 315-328. https://doi.org/10.1002/2017JD027378

Vihma, T. (2014). Effects of Arctic sea ice decline on weather and climate: A review. Surveys in Geophysics, 35, 1175-1214. https://doi.org/ $10.1007 / \mathrm{s} 10712-014-9284-0$ 